\title{
The potential of bat-watching tourism in raising public awareness towards bat conservation in the Philippines
}

\author{
Krizler C. Tanalgo ${ }^{1}$ and Alice Hughes ${ }^{1}$ \\ ${ }^{1}$ Center for Integrative Conservation, Xishuangbanna Tropical Botanical \\ Garden, Chinese Academy of Sciences
}

May 4, 2021

\begin{abstract}
Wildlife-watching and ecotourism are effective approaches for improving public attitudes and raising awareness of wildlife conservation. However, the ability of wildlife tourism to enhance the conservation of less appealing taxa such as bats has rarely been examined. We sampled a total of 197 tourists in Monfort Bat Cave Sanctuary in the Philippines, the world's largest colony of Geoffroy's Rousette (Rousettus amplexicaudatus). Convenient pre/post-visit surveys were conducted to (a) explore the potential of bat-watching to raise tourists' knowledge, attitudes towards bats, and determine how perceptions vary across demographic classes; and (b) determine potential predictors of conservation willingness among sampled urban tourists. Our study observed an increase in knowledge about bats and $61 \%$ of the tourists are willing to support conservation bat protection after the bat-watching visit to the cave site. Tourists' conservation willingness was associated with age group, prior knowledge of bat ecosystem services, and perceptions about the conservation relevance of bat-watching as a conservation initiative. Our study highlights the effectiveness of short-term engagements such as bat-watching at improving human-bat interactions and suggests such programs should focus on highlighting ecosystem services and benefits of bats. However, it should be noted that we performed this study before the COVID-19 global pandemic and misinformation linking bats to the disease spread has increased since. We expect that public perception will change in the post-COVID-19 period and the conservation willingness survey should be repeated to understand how to counter misconceptions to develop effective bat conservation management in the post-COVID-19.
\end{abstract}

This manuscript is accepted in Environmental Challenges 


\section{Introduction}

Conservation biologists urgently need to develop pragmatic and science-based measures to protect remaining species and habitats from increasing degradation and loss (Ferraro, 2001). Human and public behaviour towards wildlife shape the successful conservation of species and their habitat (Clements et al., 2018; John et al., 2013). However, the public is often unaware of the numerous ecosystem services provided by the environment, which limits their conservation willingness and support (Madden, 2004). The Aichi Biodiversity Target 1 aims to address this stating that "By 2020, at the latest, people are aware of the values of biodiversity and the steps they can take to conserve and use it sustainably" (Moss et al., 2015). To develop effective conservation and management strategies, conservation biologists and policymakers must understand important drivers of human behaviour and attitudes towards species. For example, bats are often perceived as uncharismatic or even frightening by the public, and frequently misunderstood, with little recognition or attention regardless of the various ecosystem services they deliver. Bats are crucial to ecosystem functioning, especially through seed dispersal and pollination, maintaining gene flow within ecosystems, and bringing nutrients into cave ecosystems (Aziz et al., 2021; Aziz et al., 2017; Sritongchuay et al., 2016). Also, insect-eating bats suppress insect pests in the agroecosystems, thereby reducing the need for pesticide use (McCracken et al., 2012).

Negative public perceptions of bats are pervasive as a consequence of the public's lack of understanding about their economic and ecological roles (Aziz et al., 2017; Cousins and Compton, 2005; Low et al., 2021; Tanalgo and Hughes, 2019). One consequence of the lack of recognition of the services provided by bats is a deficient conservation prioritisation and funding to highlight them, and on some occasions culling of bats for a variety of unsubstantiated beliefs (Florens, 2016). In Mauritius, for example, an estimated 20,000 Pteropus niger, a species of flying fox endemic to the archipelago, have been legally persecuted without any scientific basis as a response to fruit crop loss (Florens, 2016). The association of bats to disease spread, coupled with sensationalised media coverage, has caused widespread public fear and unjustified persecution in many regions (López-Baucells et al., 2018; Racey et al., 2018).

One key measure to effectively counter public misconceptions is by raising positive perceptions of the focal species or habitat (Boso et al., 2021; Hoffmaster et al., 2016; Moss et al., 2015). There are various outlets to improve public perception toward species and promote wildlife conservation, including zoos, aquariums, and wildlife watching (Moss et al., 2015). These initiatives are widely known to promote "charismatic species" (e.g., elephants, tigers, pandas) (Colleony et al., 2017; Hausmann et al., 2017), but are very scarce for unfamiliar species like bats. Conservation education and outreach with communities have been shown to improve public understanding and acceptance of bats (Hoffmaster et al., 2016). Flying-fox 
viewing in Terengganu, Malaysia showed evidence of the potential of wildlife tourism as a conservation tool by raising public awareness and generating positive attitudes towards bats (Roslan et al., 2017). Similar to other wildlife tourism initiatives, batwatching has the potential to raise awareness about bats and promote sustainable local development, therefore facilitating their conservation if conducted effectively and with appropriate sensitivity.

Caves are widely used for ecotourism, facilitating environmental education and generating income (Bagstad and Wiederholt, 2013; Pennisi et al., 2004). In the Southwestern United States, effective examples include the Congress Avenue bridge in Austin, Texas, which generates an estimated 6.5 million USD annually from 242,000 bat viewing tourists from across America and beyond (Bagstad and Wiederholt, 2013; Pennisi et al., 2004). Ecotourism in Gunung Mulu National Park in Sarawak Malaysia includes bat emergence viewing with the area visited by an estimated 15,850 foreign and 8,815 domestic tourists annually and the generated revenues support governmental projects for the environment (Ministry of Tourism, Arts and Culture Sarawak, 2018). Cave tourism should focus on the protection and conservation of bat species and associated ecosystems to sustain related ecosystem services provisions (e.g., pollination services of cave nectar bats) (Medellin et al., 2017). Nonetheless, bat biologists are concerned about the potential negative impacts of unregulated cave tourism and religious visits, especially in key sites with high bat biodiversity (Deleva and Chaverri, 2018; Furey and Racey, 2016; Tanalgo and Hughes, 2019). Ecotourism is complex because its definition and application are regularly misused, such as where it fails to effectively communicate the importance of biodiversity conservation (Cunha, 2010; Fernandez-Llamazares et al., 2020; Kiss, 2004; Ross and Wall, 1999) and require the integration of effective conservation messaging (Fernandez-Llamazares et al., 2020). Thus, science-based frameworks and strategies are crucial for optimising the effectiveness of ecotourism not only economically, but also to facilitate the protection of species and habitats. However, there is limited knowledge on the effectiveness of bat-watching and its ability to improve human-bat relations in many parts of the world particularly in the global south (Abdul Aziz et al., 2017; Debata, 2020).

To address this gap, we performed an investigation in the world's largest bat cave colony of Geoffroy's Rousette (Rousettus amplexicaudatus) in the south of the Philippines. We expect that tourists have higher negative perceptions and show little support towards bat conservation and management. Following other studies on ecotourism (Ross and Wall, 1999), we aimed to (a) explore the potential of batwatching to raise tourists' knowledge, attitudes towards bats, and determine how perceptions vary across demographic classes; and (b) elucidate predictors of conservation willingness among sampled tourists. We hope our findings will facilitate initiatives, constructive dialogue and collaboration between conservation biologists and ecotourism managers to design effective bat-watching programs to increase pub- 
lic support for bat conservation and management.

\subsection{Study area and focal species}

We conducted our survey in the Monfort Bat Cave Sanctuary (hereafter "MBCS") (7 $7^{\circ} 09^{\prime} 53.42^{\prime}$ N, $125^{\circ} 41^{\prime} 31.99 "$ E) located on Mindanao Island, south of the Philippines. The five-chambered cave hosts the world's largest known colony of the fruit bat, Rousettus amplexicaudatus, with an estimated 1.8 to 2 million individuals (Carpenter et al., 2014). This cave was opened for tourism in early 2005 and is privately owned and protected by the Monfort family. The cave prohibits hunting and guano harvesting. The cave's chambers and mouth are vertically open, which allows tourists to view the day-roosting bats (Fig. 1). The tourism flow in MBCS varies depending on the day of the week, with 30 to 100 tourists per day. Income from bat cave tourism chiefly flows into local livelihoods (e.g., wages) and enhances the sustainability and protection of the cave site. Bat-watching also includes a brief 20-minute conservation education lecture about bats, caves, and MBCS history.

\subsection{Survey procedure and questionnaire design}

During our pilot study and validation, roughly three-quarters of the sampled tourists were unwilling to participate or did not finish their questionnaires due to limited time to respond to a lengthy questionnaire. Subsequently, we reformatted a concise questionnaire to ease readability and obtain more responses (e.g., Choi and Pak, 2005). To improve our sample size, a combination of convenience and quantitative sampling was implemented using a similar pre/post-visit survey approach of GarciaCegarra and Pacheco (2017) to assess tourist knowledge and attitude toward bats and their conservation before and after bat-watching. Visitors were asked a set of questions before a short educational session and bat watching in the cave site (previsit survey) and followed by a post-visit survey after they conclude their bat cave viewing (Fig. 2). Only responses from the revised questionnaire were used in the final analyses.

A structured questionnaire was administered face-to-face onsite with consenting tourists between November 2018 and March 2019 (Supplementary 1). The questionnaire included 16 questions divided into pre-visit and post-visit sections. Tourists' sociodemographic background (gender, age, group, educational attainment) was asked pre-visit. The second part of the pre-visit questionnaire measured motivations of tourists, prior encounters with bats, knowledge about bats (e.g., ability to recognize species, knowledge about bats, ecosystem service provisions) and conservation willingness. It can also not be assumed that all visitors were already interested in bats, as this tour was often part of a diverse tour program that visited a number of places. The pre-visit questionnaire was introduced prior to the short educational lecture by the MBCS staff, and the same questionnaire responded by the individual tourist was used in the post-visit survey. 
Tourists proceeded to the cave site for an average of 30 minutes of bat-watching activities. After the visit, tourists were requested to complete the post-visit questionnaire, which consisted of questions to determine tourist satisfaction with their visit and their perceptions of conservation values of bat-watching. To assess the effectiveness of short-term learning enhancement between visits, two questions (knowledge about bat ecosystem services, and willingness to conserve and protect bats) from the pre-visit questionnaire were repeated in the post-visit questionnaire. The questions had categorical responses ("Yes," "No," "Not sure") and responses were then coded to a three-level scoring scale (e.g., $1=$ No, $2=$ Not sure, $3=$ Yes) when necessary (Mulema et al., 2020).

\subsection{Data analyses}

First, the reliability of the statements was tested with Cronbach's $a$ and demonstrated an acceptable level of internal consistency $(a=0.75 ; \pm 0.634)$ in both previsit $(a=0.73 ; \pm 0.50)$ and post-visit $(\alpha=0.77 ; \pm 0.13)$ questionnaires (acceptable value $=0.80>\alpha>0.70)$. We characterised each visitor's perception and attitude according to their sociodemographic backgrounds (e.g., gender, group, age, educational attainment). To test for the significant difference in categorical responses based on their sociodemographic backgrounds, we used Pearson's chi-squared test of independence $\left(?^{2}\right)$.

We performed separate binomial logistic regression to determine variables that are linked to tourists' conservation willingness in the (i) pre-visit and (ii) post-visit. We pooled the responses "Not sure" with "No" and coded as "Not willing" and "Yes" as "Willing" (e.g., Carson et al., 1998 and Mulema et al., 2020) to fit with the binomial prediction following Aziz et al. (2017). We used the values obtained from mean scores of each indicator in pre-visit and post-visit variables and sociodemographic profiles as covariates and factors in the binomial logistic model. The (a) prior experience and recognition, (b) knowledge and understanding about Philippine bats, and (c) and prior knowledge of ecosystem services were used as predicting variables for pre-visit conservation willingness. Next, we used: (a) learning and aesthetic satisfaction, (b) perceptions about conservation importance, (c) enhanced knowledge of ecosystem services of bats and (d) prior knowledge about ecosystem services as predicting variables for post-visit conservation willingness.

Consequently, to determine the effectiveness of short-term enhancement of knowledge about bat ecosystem services and conservation willingness, we applied the nonparametric Wilcoxon rank test to assess the significant relationship between visits. All reliability and statistical tests were performed using the open-source program Jamovi version 1.2.6 (The Jamovi Project, 2020). We set our statistical significance at $p=.05$.

\subsection{Ethical notes}


This research follows the guidelines on ethical standards and collection of data in strict compliance to the ethical standards in handling human subjects (i.e., visitors and tourists) according to the Collaborative Institutional Training Initiative (CITI) Program for human research standards and manual (reference ID: 13047172).

\section{Results}

\subsection{Sociodemographic profile of tourists and visit motivation}

A total of 197 tourists participated in our study, composed of $62 \%$ ( $n$ $=122)$ male and $38 \%(n=75)$ female. In terms of age distribution, most of the tourists surveyed were between 20 and 40 years old (age group B: $n=120 ; 61 \%$ ) followed by above 40 (age group C: $n=46,23 \%$ ) and below 20 (age group A: $n=31$; $16 \%$ ). The distribution of tourists based on their educational background was equal between those with basic (elementary to high school education) ( $n=98,50 \%)$ and higher (college or higher) $(n=99,50 \%)$ education. While, in terms of nationality, $85 \%(n=167)$ of the visitors were Filipino and $15 \%(n=30)$ were foreigners. The motivation to visit MBCS significantly differed among tourists $\left(?^{2}=290.12, d f=\right.$ $5, p<.001)$ and the highest motivation was 'to see bats' $(n=144 ; 73 \%)$ followed by 'to see caves' $(n=104 ; 53 \%)$ and for leisure $(n=102 ; 52 \%)$. A total of $61 \%(n=$ $121)$ tourists perceived bats positively ( $p>0.05$ across demographic backgrounds). Additionally, in terms of general bat knowledge and associations, $41 \%$ of the tourists correctly perceived bats as an "animal" and the remaining $59 \%$ thought bats where "aswang" or "mananggal" (a local version of a vampire in the Philippines), but this response differed in terms of education level $\left(?^{2}=16.64, d f=3, p=.001\right)$ with higher misperception observed among sampled tourists with basic education $(n=$ $25,26 \%)$ compared to those with higher education $(n=5,5 \%)$.

\subsection{Prior encounter, recognition, and perception of bats}

More than half of the tourist participants ( $n=106 ; 54 \%)$ had seen bats before compared to $45 \%(n=87)$ who had not and $2 \%(n=4)$ who were unsure if they had prior or previously encountered bats. Within the sociodemographic class, distribution in terms of gender, which had prior encounter with bats had relatively equal percentages. However prior experience differed significantly among age groups $\left(?^{2}=12.03, d f=4, p=.02\right)$, with a higher percentage of prior experience among younger age groups (age group A, $n=17,55 \%$ ) compared to older groups (Fig. 3).

Tourists' ability to recognise bat species and differentiate between bat groups (e.g., the difference between fruit bats vs. insect bats) was significantly higher in the younger-aged group ( $13 \%$ of below 20 years old) compared to other groups $\left(?^{2}=\right.$ $13.42, d f=4, p=.01)$. When tourists were asked about their knowledge of bat diversity and distribution in the Philippines, $13 \%(n=26)$ have knowledge of bats and their diversity in the country. While there were $34 \%(n=67)$ of the sampled 
tourists understood the importance of caves as bat habitats. Filipinos ( $n=27$, $16 \%)$ showed higher knowledge on Philippine bat diversity than foreign tourists $(n$ $=0,0 \%)\left(?^{2}=6.026, d f=2, p<0.05\right)$. Similarly, Filipinos $(38 \%, n=63)$ showed higher familiarity than foreign tourists $(10 \%)$ in terms of the knowledge of cave bats in the Philippines $\left(?^{2}=8.78, d f=2, p=0.012\right)$ (Fig. 3).

\subsection{Post-visit perception, satisfaction and learning experience}

The majority ( $n=190,96 \%$ ) of the tourists were satisfied with batwatching learning experience ( $n=190, p>0.05$ across demographic backgrounds). Consequently, the overall post-visit satisfaction of tourists was $94 \%(n=185)$ and significantly differed by age $\left(?^{2}=9.36, d f=4, p<0.05\right)$ and higher satisfaction was noted among middle-aged (20-40 years old, 97\%) and older (above 40 years old, $93 \%)$ tourists. A total of $86 \%(n=169)$ of the tourists agreed that bat-watching ecotourism contributes to bat conservation and, was significantly greater among males and older respondents (above 40 years old) (age: $?^{2}=10.3, d f=4, p=$ 0.035; gender: $\left.?^{2}=10.74, d f=3, p=0.013\right)$. While $80 \%(n=158)(p>0.05$ across sociodemographic scales) of the overall sampled tourists agreed that bat cave conservation is an important initiative in the Philippines. Lastly, $80 \%(n=158)$ of the respondents perceived bat conservation as an important environmental initiative in the Philippines ( $p>0.05$ across demographic backgrounds) (Fig. 3).

\subsection{Knowledge of ecosystem services and predictors of conservation at- titude}

The tourists' knowledge about ecosystem services and willingness to conserve were measured between pre-visit and post-visit surveys. Responses did not significantly differ across sociodemographic backgrounds in both pre-visit and post-visit. In the pre-visit survey, only $36 \%(n=71)$ of the tourists showed knowledge of bat ecosystem services, $36 \%(n=71)$ were not sure and $28 \%(n=55)$ with no knowledge. The female tourists $(44 \%, n=33)$ and those with higher education $(46 \%, n=46)$ showed greater knowledge and awareness about bat ecosystem services than other participants. Post-visit, responses were consistently higher among females (91\% vs. $85 \%$ in males) with higher education $(64 \%, n=63)$ exhibited greater awareness and acquired knowledge on bat ecosystem services. Overall, the level of knowledge of ecosystem services significantly increased in the post-visit survey (Wilcoxon signedranks test, $=35.5, p<0.0001)$ with $87 \%(n=145)$ of the tourists become aware (Fig. 4).

When asked about their willingness to conserve bats, $45 \%(n=89)$ of the surveyed tourists showed willingness and a high positive response $(n=89,45 \%)$ in the previsit. A higher positive response $(65 \%, n=20)$ was noted among age group A $\left(?^{2}=\right.$ 11.01, $d f=4, p=0.03)$ and significantly lower willingness among sampled tourists with basic education ( $21 \%$ vs. $8 \%$ higher education) $\left(?^{2}=7.97, d f=4, p=0.02\right)$. Only age showed significant relationship to post-visit conservation willingness $\left(?^{2}=\right.$ 
13.70, $d f=4, p=0.01)$.

The conservation willingness of tourists was assessed both pre-visit and post-visit. The separate logistic regression models showed significance in predicting the overall conservation willingness of tourists before and after they visited the bat cave (Table 1 and 2 , respectively). In the pre-visit model, the age group A versus the reference age group $\mathrm{B}$ showed significance association to the dependent variable $(p=0.007, \beta$ $=1.40, \mathrm{OR}=4.05)$; prior knowledge on bat ecosystem services also showed positive association to tourists' conservation willingness $(p<0.0001, \beta=1.66$, OR $=5.25)$ (Table 1).

In the post-visit model, age group was a marginally significant predictor (age group A to $\mathrm{B}, p<0.06, \beta=1.145, \mathrm{OR}=3.14$ ). The perception of conservation importance of bat cave tourism showed a strong and positive association to conservation willingness in the post-visit analysis $(p<0.004, \beta=4.08$, $\mathrm{OR}=59.06)$. Prior knowledge about bat ecosystem services $(p<0.02, \beta=0.58, \mathrm{OR}=1.79)$ remained a good predictor of conservation willingness and compared to the post-visit knowledge on bat ecosystem services that showed no association (Table 2). Yet, there was a significant increase in tourists with conservation willingness at $61 \%$ post-visit from $45 \%$ $(+16 \%)$ in the pre-visit, and increased level of awareness (Wilcoxon signed-ranks test, $Z=261, p<0.0001$ ) (Fig. 4) indicating the effectiveness of the bat-watching in changing tourist perception.

\section{Discussion}

\subsection{Tourist attitude and perception of bats}

Our study demonstrates the potential of bat-watching ecotourism to improve public knowledge and conservation willingness of the public towards bats in the Philippines. The public perception of bats has an important impact on their conservation (Aziz et al., 2017; López-Baucells et al., 2018; Low et al., 2021). Bat watching was the primary motivation of tourists to visit MBCS, suggesting prior interest to bats by the visiting tourists. Contrary to our expectations, this study revealed that more tourists have favourable and positive perception towards bats than reported in many studies (Musila et al., 2018; Tanalgo et al., 2016).We found a more positive perception among highly educated respondents than those with basic education. This can be associated with their prior experience or higher access to knowledge from their educational experience or background giving them a higher level of understanding of the natural world (Lim and Wilson, 2019). In the Philippines, Tanalgo et al. (2016) found that respondents with higher education had a lower willingness to participate in bat hunting activities or consume bats for subsistence compared to those with lower education level. Public negative behaviour towards wildlife is driven by the greater likelihood of encounter and thus the possibility of negative experiences (Aziz et al., 2017, 2016; Kellert et al., 1996; Tanalgo et al., 2016; Zaradic et al., 2009). Similar findings by (Tanalgo et al., 2016), 
showed that local communities living near caves with large colonies of bats had more negative perceptions towards bats than those living further away, and promote intentional culling because they believe that bats were responsible for destroying their fruit orchards. In Malaysia, local communities in Tioman Island tend to have a negative perception towards co-existing with Flying foxes because of their noise and destruction of fruit crops (Aziz et al., 2017). Similarly, in Australia, people tend to develop a negative perception of flying foxes after roosts move into residential communities in urban areas (Tait et al., 2014).

We found Filipino tourists were more familiar with Philippine bat species than foreign tourists. The support and involvement of locals are vital for the effective conservation of wildlife populations and their habitats. Local citizens have more exposure to their local biodiversity and environment, and therefore develop a higher familiarity and understanding of it (Karanth and Nepal, 2012; Souto and Ticktin, 2012; Theobald et al., 2015). Furthermore, locals may have key roles in species conservation (Raymundo and Caballes, 2016) but this may differ based on cultural values and experience (Tanalgo et al., 2016; Tanalgo, 2017). However, our analysis shows that prior experience or exposure with bats was not directly associated with urban tourists' conservation willingness, which mirrored tourists' general lack of experience with bats. People's willingness to support species conservation depends on their knowledge about the importance of species which varies in social backgrounds (Lindemann-Matthies and Bose, 2008). For example, urban dwellers have a lower understanding of wildlife than rural areas because they have less exposure to natural environments (Kato et al., 2019). In our present study, prior knowledge of ecosystem services was an important predictor of conservation willingness before and after bat-watching suggesting the importance of long-term knowledge. In addition to this, the perception of the conservation relevance of bat-watching to bats and caves as a conservation initiative was a strong predictor of conservation willingness among tourists. This suggests that the public willingness to support bat management initiatives can be facilitated by wildlife tourism platforms to enable more effective conservation and management (Lundberg et al., 2019).

Conservation willingness differed by age and educational attainment. We found greater conservation willingness among tourists with higher education attainment. This is comparable to the findings of Musila et al. (2018) in Africa showing that older adults with higher educational attainment have a more positive perception and support for bat conservation. But in our study, younger $(<20$ years old) urban tourists showed higher conservation willingness. One plausible reason that drives younger tourists' association to conservation willingness was their access to environmental science education from secondary to tertiary education, which is included in the modern Philippine educational curriculum. Previous studies showed that younger respondents exposed to environment-related activities or education tend to have increased pro-environmental attitudes (Lieflander and Bogner, 2014) 
and nature connectedness (Grantzdorffer et al., 2019; Lieflander and Bogner, 2014). The younger age group is ideal demographics for sharing conservation awareness and higher influence in changing adult behaviour towards environmental conservation (Damerell et al., 2013). Ideally, adapting bat-watching activities friendly for the younger audience could positively affect and enhance their connectedness to "uncharismatic" species, thereby facilitating their conservation. This is important, given that a lack of information and understanding can only drive fear and distrust, which act as barriers to conservation.

Our study showed that a large proportion of tourists were satisfied with bat-watching and learnt more about bats. In the post-visit survey, we noted that sampled tourists frequently showed higher support for bat conservation management and increased positive perception towards cave and bat conservation (e.g., a 16\% increase in the number of tourists willing to conserve bats). Though it is difficult to conclude if the observed positive change in level perception is high or low due to limited studies on bat ecotourism, our findings will serve as a baseline for future studies investigating the association of ecotourism to raising public awareness and support towards bat conservation. Further, we suggest that integrative conservation education (e.g., detailing bat ecosystem services) and experience-based approaches such as bat cave watching, and tours could be useful to bolster human-bat relations (Musila et al., 2018; Trewhella et al., 2005).

\subsection{Balancing ecotourism and conservation}

Urban tourists perceive bat-watching as an important initiative to raise awareness for bat conservation, however, we caution on balancing the positive and negative impacts of bat-watching tourism to bat population and cave ecosystems (Fig. 5). To effectively sustain ecotourism, it should follow regulations and focus on conservation or preservation of natural resources (Kiss, 2004; Ross and Wall, 1999). Cave tourism is among the key threats for global bats that can stem from a lack of sustainable management (Furey and Racey, 2016; Tanalgo et al., 2018). The apparent impact of cave ecotourism on bats occurs when visitors introduce loud noises, add light and cause environmental and atmospheric changes (Cardiff et al., 2009). These have detrimental effects on bat physiology and behaviour (Speakman et al., 1991) and altering reproductive success and patterns of bats (Lim et al., 2018). The negative impacts of unregulated cave tourism and religious activities have greater implications in regions where such activities are famous, and there is high reproductive synchrony among species (e.g., in Southeast Asia) (Lim et al., 2018). Likewise, cave tourism increases emerging disease transmission risks spatially and between humans and bats (e.g., White-nose syndrome in North American bats) (Julg et al., 2008; Lorch et al., 2016) and may cause bats to shift roosts and thus further impact population health and viability. Furthermore, the consequences of the alteration in bat biology and ecology caused by unregulated tourism have drastic impacts on populations (Phelps et al., 2018, 2016) and of the provision of their ecosystem 
services (Sritongchuay et al., 2016). Regulating tourist activities, human-made infrastructure and illumination inside the cave are crucial to sustainably manage caves (Gillieson, 2011).

\section{Conclusion: synthesis and implication for post-COVID-19 conser- vation management}

The potential of ecotourism as a tool for improving human-bat relations was explored in this study. Specifically, our study showed the effectiveness of short-term engagement approaches such as bat-watching by increasing tourists' awareness and conservation willingness towards bats. We noted varying levels of knowledge and public perceptions towards bats and the association with sociodemographic backgrounds. But most importantly tourists' conservation willingness towards bat conservation was driven by their knowledge of bat ecosystem services, and their perception of the conservation relevance of bat cave watching. Our findings conform to one of the paradigms (i.e., to affect nature conservation) of genuine purpose and application of ecotourism (Ross and Wall, 1999). However, further work is needed, as we only targeted urban tourists using key knowledge indicators. Further, in-depth and comparative studies (e.g., different geographic and cultural backgrounds) on conservation effectiveness of ecotourism to raising conservation willingness and interest should be developed. Our findings showed that most of the tourists perceive bats positively. It is critical to take note that public behaviour towards wildlife may change depending on the current societal and economic trends (Manfredo et al., 2003). Although bats were previously feared due to their association with disease, this has exacerbated during the COVID-19 pandemic (Zhou et al., 2020). The fear-mongering portrayal by various media platforms has spread more rapidly than the virus itself and has led to a public backlash and calls for colony executions and culls (Zhao, 2020). The global bat conservation community expects significant changes in public behaviour towards bats, which may hamper conservation. Thus, we suggest that a survey on tourist's perception and behaviour towards bats in the post-COVID-19 period would enable further measures to be developed to improve people's perceptions of bats, and thus enable conservation biologists and tourism managers to develop appropriate measures ensuring the protection of bats and facilitate sustainable tourism.

Bat conservationists and science communicators thus need to take this as an important measure to counter misinformation, bolster or restore positive connections between human and bats in the post-COVID-19. Prudent and unprejudiced framing of information should be emphasised when communicating about bats and COVID19 issues to the public (see MacFarlane and Rocha 2020), as well as the almost non-existent risk, provided basic measures are taken (as is true with all wildlife). Primarily, conservation communication should highlight comprehensible information about the ecological and economic roles of bats, the human-bat disease dimensions, and the role of human activities (e.g., wildlife meat trade and habitat destruction) 
on increasing disease risks, and the value of OneHealth approaches. Effectively and positively engaging humans with bats will be key to their effective conservation, here we demonstrate that ecotourism can play that role and could enable a better and safer co-existence for both taxa.

\section{References}

\section{List of Figures}

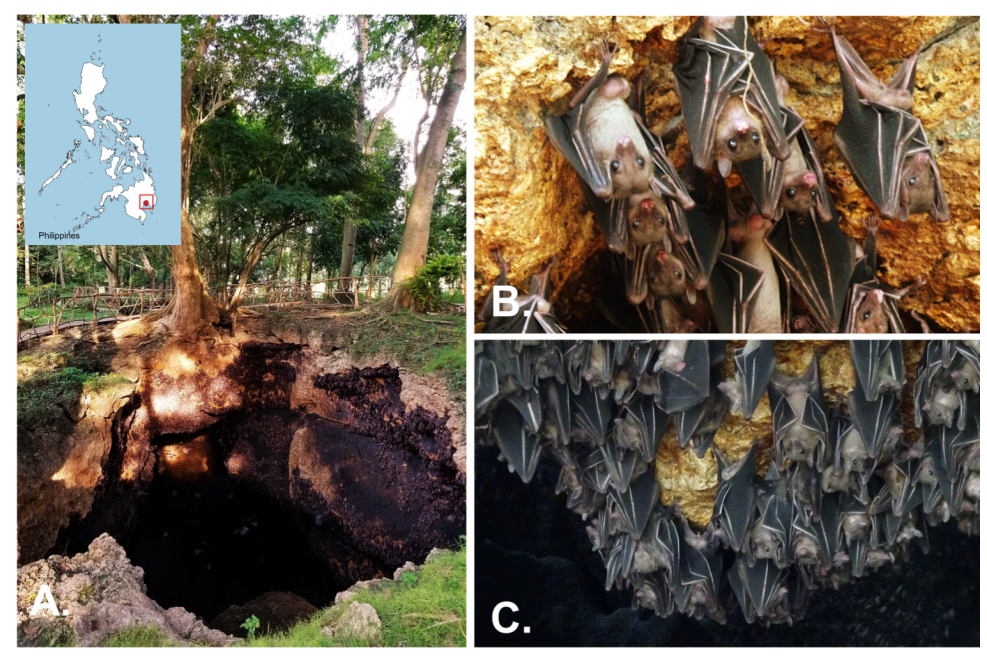

Figure 1: This is Location of the study site. Monfort Bat Cave Sanctuary (MBCS) is located in the Southern part of the Philippines (A-B) and holds the world record for the largest colony for the fruit bat species Rousettus amplexicaudatus (C-D.) a caption 


\section{Entrance briefing by MBCS staff}

\section{Pre-visit survey}

\section{Conservation education lecture (10 mins)}

- Introduction about the bats and the

Monfort bat cave sanctuary

- General biology, ecology, ecosystem

services of bats and the focal species, Rousettus amplexicaudatus

- Ecosystem services by bats such as pollination of Durian

- Fun facts about bats

- Guidelines on bat cave watching (e.g., do's and don'ts

\section{Bat cave watching (20-30 mins.)}

\section{Post-visit survey}

Figure 2: This is a A flow diagram showing the sequence of tourist bat-watching visit and pre/post-visit survey in Monfort Bat Cave Sanctuary. 


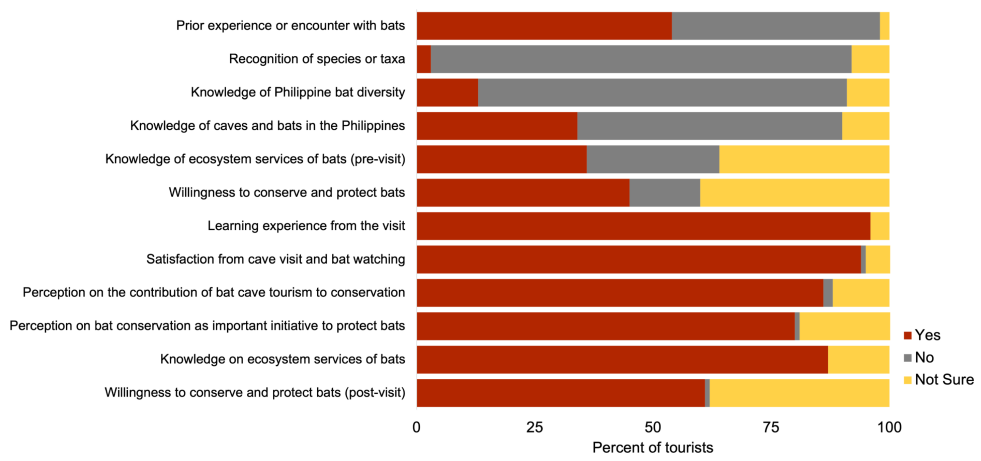

Figure 3: Distribution of visitors' responses in different indicators between pre/postvisit surveys, expressed in percentage (\%) of responses. 


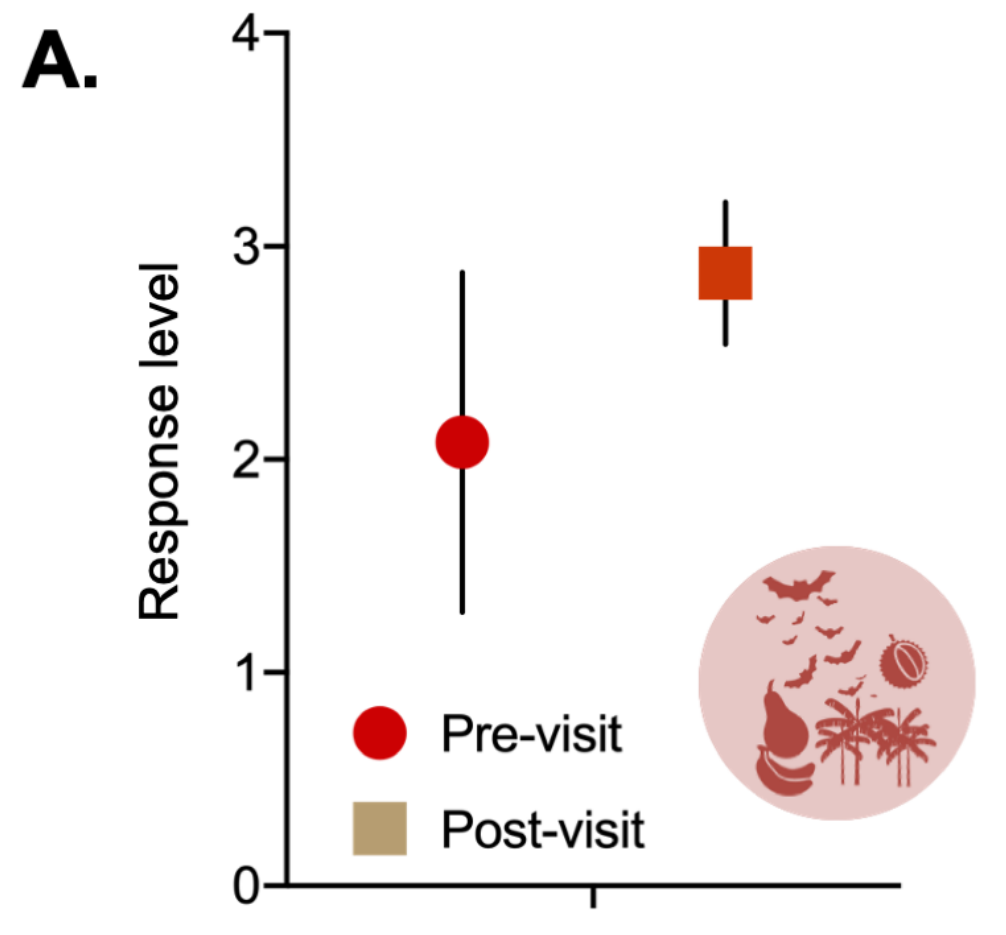

Ecosystem services knowledge

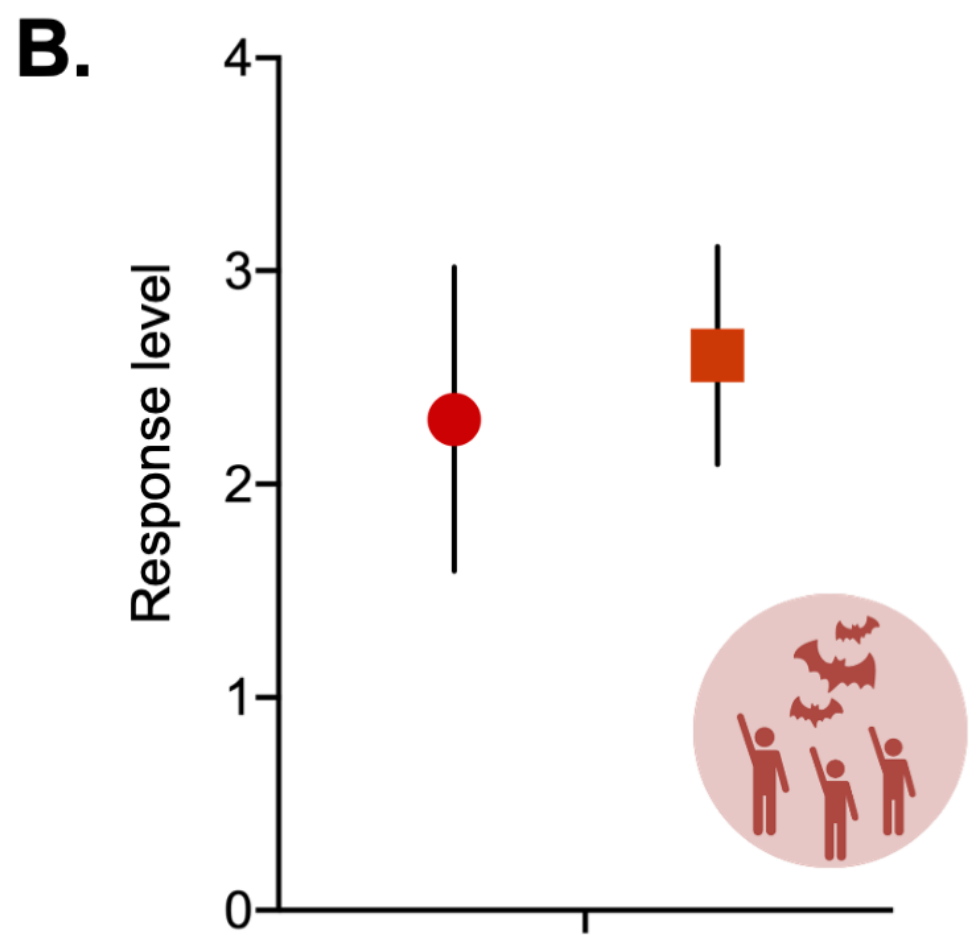

\section{Willingness to conservation}

Figure 4: The comparison of tourist' level of knowledge on ecosystem knowledge (A) and conservation willingness (B) between pre-visit and post-visit surveys. 


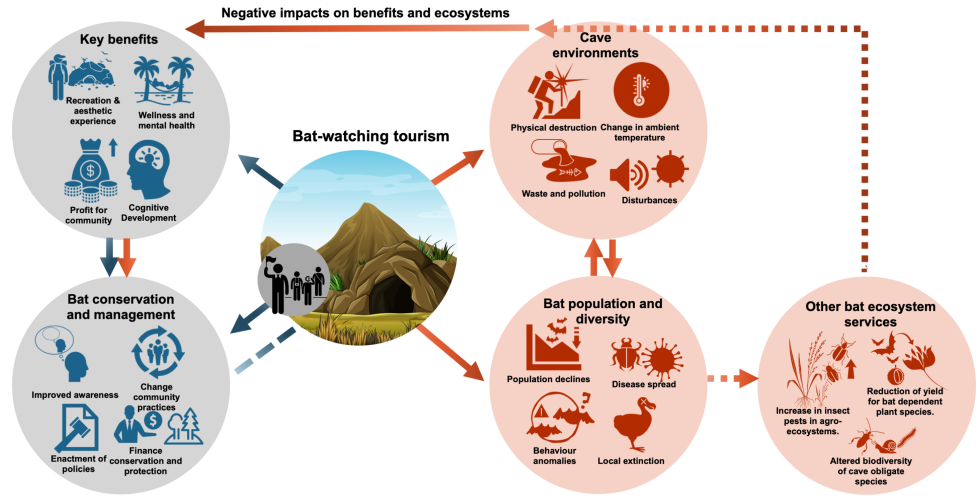

Figure 5: Balancing bat-cave tourism benefits. A schematic diagram showing the potential benefits and the negative impacts of unregulated bat-watching tourism in caves.

\section{List of Tables}

Table 1 . Results of generalised linear modelling on the conservation willingness of MBCS visitors during the pre-visit survey. Values highlighted in bold were significant at $p<0.05$. Model fit measures: $\mathrm{AIC}=236.01$, ? $2=53.26, \mathrm{df}=8, \mathrm{p}<.001$, Nagelkerke pseudo $\mathrm{R}^{2}=0.32$. Note: Age group $\mathrm{A}=<20$ years old, B 20-40 years old $=, \mathrm{C}=>40$ years old.

\begin{tabular}{lllll}
\hline Predicting variables & $\beta$ & $\mathbf{S E}$ & $\mathbf{p}$ & $\mathbf{O R}$ \\
\hline Gender: & & & & \\
Female - Male & -0.11 & 0.35 & 0.76 & 0.90 \\
Group: & & & & \\
Foreigner - Filipino & -0.06 & 0.49 & 0.90 & 0.94 \\
Age group: & & & & \\
A - B & $\mathbf{1 . 4}$ & $\mathbf{0 . 5 2}$ & $\mathbf{0 . 0 1}$ & $\mathbf{4 . 0 5}$ \\
C - B & 0.5 & 0.40 & 0.21 & 1.66 \\
Education level: & & & & \\
Higher - Basic & -0.48 & 0.38 & 0.21 & 0.62 \\
Prior experience and recognition & -0.33 & 0.37 & 0.37 & 0.72 \\
Knowledge of bat diversity and caves in the Philippines & -0.29 & 0.30 & 0.35 & 0.75 \\
Prior knowledge on ecosystem services by bats & $\mathbf{1 . 6 6}$ & $\mathbf{0 . 3}$ & $<\mathbf{. 0 0 1}$ & $\mathbf{5 . 2 5}$ \\
\hline
\end{tabular}

Table 2. Results of generalised linear modelling on the conservation willingness of MBCS visitors in the post-visit. Values highlighted in bold were significant at $p<$ 0.05. Model fit measures: $\mathrm{AIC}=195.19$, ?2 $=87.54$, df $=9, \mathrm{p}<.001$, Nagelkerke pseudo $\mathrm{R}^{2}=.49$. Note: Age group $\mathrm{A}=<20$ years old, $\mathrm{B}=20-40$ years old $=, \mathrm{C}=$ 
$>40$ years old.

\begin{tabular}{lllll}
\hline Predicting variables & $\beta$ & SE & p & OR \\
\hline Gender: & & & & \\
Female - Male & 0.06 & 0.40 & 0.88 & 1.06 \\
Group: & & & & \\
Foreigner - Filipino & -0.37 & 0.52 & 0.48 & 0.69 \\
Age group: & & & & \\
A - B & 1.15 & 0.62 & 0.06 & 3.14 \\
C - B & 0.45 & 0.48 & 0.36 & 1.56 \\
Education level: & & & & \\
Higher - Basic & 0.25 & 0.41 & 0.54 & 1.29 \\
Learning and satisfaction values & -0.75 & 1.82 & 0.68 & 0.47 \\
Perception of the relevance to conservation & $\mathbf{4 . 0 8}$ & $\mathbf{1 . 4 3}$ & $<\mathbf{0 . 0 1}$ & $\mathbf{5 9 . 0 6}$ \\
Prior knowledge on ecosystem services by bats & $\mathbf{0 . 5 8}$ & $\mathbf{0 . 2 4}$ & $\mathbf{0 . 0 2}$ & $\mathbf{1 . 7 9}$ \\
Enhanced knowledge on ecosystem services by bats & 17.33 & 1116.71 & 0.99 & $<1.00$ \\
\hline
\end{tabular}

